\title{
VARELA, Ângela. Configurações do poema em prosa: de "Notas marginais" de Eça ao Livro do desassossego de Pessoa. Lisboa: Imprensa Nacional / Casa da Moeda, 2011.
}

\section{Luisa Destri}

Universidade de São Paulo (USP), São Paulo, São Paulo, Brasil luisadestri@gmail.com

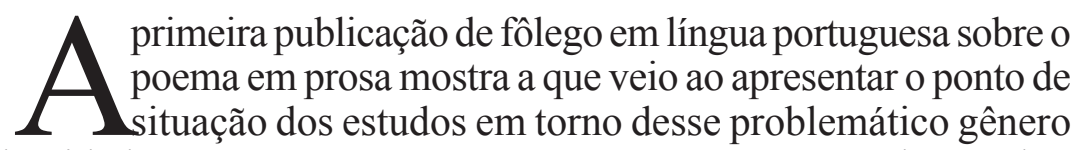
da modernidade: "não apareceu até ao presente [entre nós] nenhuma obra inovadora que conjugue as dimensões teórica e histórica com a noção concreta pela qual o gênero poderá se questionar, ou mesmo continuar, em cada autor" (30). ${ }^{1}$ Não parece injusto sugerir que Configurações do poema em prosa: de "Notas marginais" de Eça ao Livro do desassossego de Pessoa, de Ângela Varela, deseje ocupar essa lacuna - aliás, parece oportuno lê-lo de acordo com essa proposição.

Tendo como principal objetivo identificar a particularidade com que a literatura portuguesa continuou a tradição francesa (o poema em prosa surge como gênero com Baudelaire, que em 1862 confessa tomar como modelo para Spleen de Paris a obra Gaspard de la nuit, de Aloysius Bertrand, de 1842), a autora efetua primeiramente uma consistente revisão bibliográfica, como não poderia deixar de ocorrer num caso em que o objeto de estudo conta já com importante bibliografia, mas ainda inédita em nossa língua. Assim, partindo do seminal Le poème en prose: de Baudelaire jusqu'à nos jours, de Suzanne Bernard, publicado em 1959, reconstitui a apaixonada discussão em torno da escrita poética que, desde seu nome, encena a crise dos gêneros na modernidade. Nesse percurso, abarcando inclusive a produção acadêmica francesa mais recente, passa pela Espanha (onde a referência é Teoría del poema en prosa, de María Victoria Utrera Torremocha) e pelo Brasil, onde apenas agora se desenvolve crítica a respeito.

\footnotetext{
${ }^{1}$ Os números entre parênteses referem sempre à página, na obra resenhada, de onde foram extraídas as citações.
} 
No confronto entre um e outro crítico dedicado ao mesmo objeto, e ainda antes de chegar ao conteúdo propriamente autoral da obra - isto é, entre a revisão bibliográfica e a introdução -, logo se coloca o cerne do posicionamento da autora. Se a certa altura afirma que "não será definitiva uma definição do poema em prosa" (42), pois não se trata de propô-la, muitas vezes revela afinidade profunda com o estudo de Suzanne Bernard, que define o gênero pela brevidade, intensidade e concisão: "[o poema em prosa] é um texto necessariamente breve e fechado em si mesmo, logo, independente de qualquer enquadramento contextual, marcado pela tensão operada pelos seus artifícios semânticos e rítmicos” (41).

As análises do corpus são antecedidas por um primeiro capítulo dedicado à discussão genológica. Em modalidades tradicionais da prosa e da poesia a autora busca gêneros que, prenunciando o "conflito de códigos", constituiriam possíveis origens do poema em prosa. O romance e o conto poéticos, os fragmentos líricos de narrativas em prosa, o quadro descritivo da natureza, a página de diário e a canção lírica servem então a dois propósitos principais: o primeiro deles, "confirmar a definição inicial do poema em prosa - como gênero híbrido e oximórico -, que participa da prosa e da poesia pela fusão dos contrários" (143). Neste movimento, o raciocínio circular estabelece uma espécie de tautologia com as questões introdutórias. Mas o projeto geral do livro - buscar as origens do poema em prosa - ampara-se nas discussões sobre os gêneros em particular. Assim, na sequência, Varela passa a investigar algumas modalidades: a canção em prosa, a micronarrativa poética, o retratopoema, o quadro cênico, o quadro-canção e o diário-poema reflexivo.

Conforme anuncia o subtítulo da obra, com Eça de Queirós se inaugurou o poema em prosa na literatura portuguesa. "Notas marginais" - a estreia mesma do autor de Os maias na literatura, conjunto de 22 breves textos publicado em 1866 na Gazeta de Portugal e posteriormente reunido em Prosas bárbaras, é classificado pela autora como uma sequência de canções em prosa: recursos de repetição, analogias, paralelismo e enumeração revelam que esse subgênero filia-se à mais pura tradição lírica.

"Notas marginais" se inicia com fragmentos de um poema em verso, cuja função no conjunto é prontamente explicada por um narrador: "Na margem do papel marcado, onde se viam ainda estes restos de uma velha cantiga, alguém escreveu estas notas desordenadas e bizarras".

${ }^{2}$ QUEIRÓS, s/d, p. 20. 
Se "marginais" pode referir o estatuto mesmo do gênero ali praticado, há também, portanto, um sentido literal para o título. As referidas notas são os fragmentos que lemos como poemas sem versos, todos dedicados ao tema amoroso: uma primeira metade centra-se nas expectativas do eu lírico; a outra, no sofrimento provocado pela separação entre os amantes.

Varela discute todos os fragmentos, mostrando como o léxico afetivo recupera os modelos tradicionais da canção, como os recursos de repetição the reproduzem o andamento e como as estrofes se articulam pela reiteração de motivos, não pelo andamento narrativo ou o encadeamento típicos da prosa. Nos melhores momentos, as análises mostram como o tema essencial da canção - o amor - põe-se também a serviço da reflexão metalinguística. A respeito da nota VI, por exemplo, a autora argumenta o topos da desilusão amorosa como analogia entre a impossibilidade de completude e a inatingível perfeição artística ("Mas se me dizes que me queres muito, sinto que vem logo um estranho Inverno descorar-me as faces, desfolhar-me a alma de todas as emoções e cobrir de geada todos os loucos desejos", canta o poeta).

Em outros momentos, no entanto, a interpretação traz a marca de certo engessamento de pressupostos. A leitura se apoia na dicotomia espiritualismo/materialismo, que, segundo Varela, é fundamental à obra queirosiana, e se desenvolve de modo a revelar nesses escritos da juventude a presença de um tema caro ao prosador maduro - a imagem demoníaca da mulher, tal como surgirá exemplarmente no conto "Singularidades de uma rapariga loira". No que diz respeito a "Notas marginais", o efeito mais patente da leitura previamente dirigida ocorre em torno do poema V. Projetando o motivo do sofrimento causado pela mulher sobre a expressão do eu lírico, a autora deixa escapar uma poderosa sugestão erótica.

O poema compara os desejos da amada a flores ("De cada um de teus desejos nascia uma flor"), e em seguida toma o vento como metáfora para o amante ("E os meus suspiros, como a aragem serena da tarde, embalavam docemente aquelas flores virginais"). As estrofes finais dedicam-se aos efeitos do vento quanto toca as flores:

E as magnólias iam crescendo até se tornarem numa árvore imensa. Então o vento enroscava-se pelo tronco, pendurava-se nos ramos e espalmava-se nas folhas sonoras.

E então a árvore estremecia, como num sonho agitado - 
depois adormecia - e dava em redor uma sombra serena e Consoladora. ${ }^{3}$

Varela aponta a dimensão erótica das magnólias abraçadas pelo vento, mas considera que o "sonho agitado" se deva ao anúncio da desilusão, e não ao toque do amante. A atenção ao indiscreto jogo de metáforas e comparações estabelece a fronteira entre a leitura que considera o texto da juventude pelo que é e o interesse despertado pela parcela de futuro que deixa entrever.

Algo semelhante ocorre em "Farsas", também de Eça, igualmente publicado na Gazeta de Portugal e reunido em Prosas bárbaras. Pelos breves textos passeiam figuras como "A ladra", "O pobre sábio" e "O poeta lírico", em episódios que revelam em chave grotesca a miséria humana ou social vivida por personagens marginalizadas. A autora analisa três dos onze fragmentos, pois nos restantes, sustenta, não há "recriação poética suficiente que evite a banalidade temática e formal” (210).

A justificativa para o recorte é novamente dada pela visada global da obra. Ao ler "Farsas" segundo a dicotomia espiritualismo/ materialismo, a intérprete releva o motivo da miséria: ora é força que, vitimizando a mulher, leva-a a tornar-se fatal; ora é esquemática oposição entre "domínio mitificado da imaginação" e "crua realidade institucional" (214), jamais se fixando como centro da leitura. Qualquer problematização se reduz, assim, a um mero jogo de opostos. Em um texto como "A forma", cujo estribilho "mas era pobre" retrata o destino duplamente cruel de uma mulher - não se casou por ser pobre; não se salvou por não ter-se casado -, a identificação do conflito fica reduzida ao par alma e corpo.

Podem parecer menores as divergências de interpretação - que, ademais, existem em qualquer caso de análise literária. No estudo de Varela, porém, a estratégia central reside justamente na compreensão das peças em particular. Os textos do corpus - formado ainda por escritos de Guilherme Gama, Eduardo Barros Lobo, Almada Negreiros, Teixeira de Pascoaes e Bernardo Soares/Fernando Pessoa -, servem a dois objetivos principais. O primeiro deles, demonstrar, na esteira do argumento de Suzanne Bernard, que as composições, sendo concisas, sugestivas e independentes, configuram-se como poemas em prosa. O outro é uma espécie de demonstração por acúmulo: ao deter-se com minúcia nos

${ }^{3}$ QUEIRÓS, s/d, p. 20. 
aspectos estilísticos, a autora demonstra que a linguagem em questão é poética, e não prosaica, o que bastaria à classificação do gênero.

Em outras palavras, a argumentação assume o seguinte caminho: após identificar as matrizes do poema em prosa, predominantemente prosaicas, a autora seleciona obras que, escritas em prosa, apresentam a densidade e a circularidade próprias da poesia. Já não se trata de discutir a necessidade de presença ou ausência de versos, mas de demonstrar a acomodação da linguagem poética no discurso retilíneo da prosa. Comprove-se o raciocínio na seguinte passagem, ainda a respeito de Eça de Queirós:

[...] nestes fragmentos a densidade da escrita é proporcional à concentração do texto. O mesmo efeito é conseguido no poema em parágrafos, pelos quais se depura, através dos brancos, uma composição mais extensa [...]. Dentro deste grupo incluem-se vários poemas de "Notas marginais", os quais, pela geométrica estrutura formal (com simetrias, enumerações, reiteração de vocábulos e de segmentos frásicos), poderiam dispor-se em estrofes, ou até em versos (276).

Dispor-se ou não em versos é o dilema próprio ao poema em prosa, já que o conflito de códigos se dá como busca pela tensão, e não como escolha indiferente. Nada impede que se identifique no corpus o insuficiente aproveitamento do problemático gênero, mas não parece ser este o posicionamento da autora. No caso de "Farsas", a interpretação segundo traços gerais da obra queirosiana afasta a problematização da miséria: presente em cada fragmento, não poderia ser um indício de que a pobreza estilística, ou a sua aparência, é um efeito conscientemente almejado - aliás conscientemente buscado por meio do poema em prosa? Neste caso, a fatura aparentemente simples e trivial seria inerente à farsa, cujo código assenta com o caráter essencialmente baixo das situações retratadas. Essa leitura é corroborada pelas palavras que encerram o conjunto: "Tristes histórias! Sofrer, chorar, ter fome e frio, e morrer à míngua, e ter noites de agonia - o que é que isto prova? Nada, nada, meus senhores. / Words! Words! Words!, dizia o nostálgico Hamlet". ${ }^{4}$

Na conclusão do estudo, Varela chega mesmo a propor uma nova nomenclatura para o gênero: poema livre, em vez de poema em prosa, já que sua configuração não obedece a nada além do propósito de cada

${ }^{4}$ QUEIRÓS, s/d, p. 53. 
autor. Assim, diferentemente do poema em versos livres, cuja liberdade é essencialmente falsa, porque criadora de seus próprios pressupostos, a composição sem versos seria determinada meramente por uma preferência autoral, inquestionável (ou ao menos não questionada).

É compreensível que, ao entender essa escrita particular como um esforço da prosa para se aproximar da poesia (e não como um trabalho poético que almeja o conflito de gêneros), Varela não problematize as razões particulares da forma. Conclui, assim, que o Livro do desassossego, de Bernardo Soares/Fernando Pessoa, é composto de poemas em prosa, entre gêneros variados, porque as dimensões fônica e rítmica sobressaem do discurso prosaico, formando cada fragmento um fim em si mesmo; já Teixeira de Pascoaes, com Verbo escuro, pratica o gênero ao explorar, a partir do texto sem versos, a mancha gráfica da página.

A densidade lírica dos textos analisados leva então a autora a formular a particularidade do poema em prosa português. Seguindo o duplo caminho aberto por Eça de Queirós (o mais próximo da canção, como em "Notas marginais", ou o derivado da prosa, como em "Farsas"), os praticantes lusitanos do gênero privilegiam "a expressão rítmica-emocional" (479). Diferentemente dos precursores franceses, mais interessados na "densidade semântica", e por isso provocando a "predominância do pensamento", os portugueses consideram igualmente as componentes rítmica e semântica, em construções que privilegiam a emoção, "visto esta, apesar de trabalhada pela retórica do poema, tender a exprimir vivências próprias" (483-484).

É natural que não reste a Varela outra opção senão afirmar, feitas as exceções a Herberto Hélder, Luís Miguel Nava e António Ramos Rosa, que o poema em prosa "não é representativo das tendências atuais da poesia em Portugal". Se o estudo é excelente em apresentar as dimensões teórica e histórica implicadas no nascimento do gênero, a falta de problematização sobre o que determina a ausência de versos impede que se formule "a noção concreta pela qual o gênero poderá se questionar, ou mesmo continuar, em cada autor" (487). Ao poema em versos cabe criar os pressupostos para o limite métrico; por que o poema em prosa, problemático por natureza, estaria entregue sem contradições à livre vontade do autor? Mais que escolha, dispor ou não em versos é genuína questão. 


\section{Referências}

BAUDELAIRE, Charles. O Spleen de Paris ou Pequenos poemas em prosa. Tradução de António Pinheiro Guimarães. Lisboa: Relógio d'Água, 1991.

BERNARD, Suzanne. Le Poème en Prose: de Baudelaire jusqu'à nos Jours. Paris: Librairie A.-G. Nizet, 1994.

BERTRAND, Aloysius. Gaspard de la Nuit. Paris: Aubry, 1943.

QUEIRÓS, Eça. Prosas bárbaras. s/d. Disponível em: <http://www. dominiopublico.gov.br/pesquisa/DetalheObraForm.do?select action=\&co_obra=14022>. Acesso em: 25 jul. 2014.

TORREMOCHA, María Victoria Utrera. Teoría del poema en prosa. Sevilla: Universidad de Sevilla, 1999. 
